\title{
Arma-Arch Modeling Of The Returns Of First Bank Of Nigeria
}

\author{
Emmanuel Alphonsus Akpan \\ Imoh Udo Moffat
}

Department of Mathematics and Statistics University of Uyo, Nigeria

Ntiedo Bassey Ekpo

Department of Banking and Finance, University of Uyo, Nigeria

doi: 10.19044/esj.2016.v12n18p257 URL:http://dx.doi.org/10.19044/esj.2016.v12n18p257

\begin{abstract}
This study looks at a possible combination of both the ARMA and ARCH-types models to form a single model such as ARMA-ARCH that will completely model the linear and non-linear features of financial data. The data used for this study are daily closing share prices of First Bank of Nigeria plc from January 4, 2000 to December 31, 2013 and were obtained from the Nigerian Stock Exchange. The share price series was found to be nonstationary while the returns series which is the first difference of log of the share price series was found to be stationary. This study provides evidence to show that $\operatorname{ARMA}(2,2)$ model is found to be adequate in the modeling the linear dependence in the returns of First Bank of Nigeria while the ARCH(1) model is adequate in modeling the changing conditional variance in the returns of First Bank of Nigeria. Therefore, combining the two models results in a single ARMA(2,2)-ARCH(1) model that completely models the returns series of First Bank of Nigeria.
\end{abstract}

Keywords: ARMA model; ARCH model; linear dependence; conditional variance; First Bank of Nigeria

\section{Introduction}

Linear time series models are not good models for describing certain characteristics of a volatility series in that in ARMA models, it is assumed that linear dependence is present in the observations. Also, assumption of homoscedasticity is not appropriate when using financial data. For instance, returns typically exhibit linear dependence as such ARMA models are natural candidates for modeling the linear dependence in financial data. However, financial data frequently exhibit volatility clustering leading to the violation of the assumption of constant variance thus making a way for the 
use of non-linear models such as ARCH, GARCH and EGARCH to model the changing variance exhibiting by financial data. The ARCH-type models are not usually used by themselves to describe a financial time series data. Therefore, in this paper, we are looking at a possible combination of both the ARMA and ARCH-types models to form a single model such as ARMA$\mathrm{ARCH}$ that will completely model the linear and non-linear features of financial data.

\section{Review Of Literature}

A drawback of linear stationary models is their failure to account for changing variance. ARCH family models are good candidates for modeling and estimating changing variance in emerging markets. According to Asteriou and Hall (2007), neglecting the presence of ARCH (autoregressive conditional heteroscedasticity) effects in regression models results in inefficient ordinary least squares estimates yet being consistent. The covariance matrix of the parameters would be biased with invalid t-statistics. Besides the lack of asymptotic efficiency, it might also lead to overparameterization of an (ARMA) model and to over-rejection of conventional tests, for example tests for serial correlation (Fan and Yao, 2005). Setting up a model which explicitly accounts for the presence of Autoregressive Conditional Heteroscedasticity (ARCH) effects leads to an efficient estimator and will ensure the calculation of a valid covariance matrix. However, such a model is usually not estimated by an ordinary least squared estimator, but by the iterative solving of a nonlinear maximation problem, namely by using a maximum-likelihood procedure (Brunhart, 2011).

Mgbame and Ikhatua (2014) studied the accounting information and stock volatility in the Nigerian Capital Market using a GARCH analysis approach. The results provide evidence to show volatility clustering, leptokurtic distribution and leverage effects for the Nigerian stock returns data.

Atoi (2014) while testing volatility in Nigerian Stock Market using GARCH models found that volatility clustering, leptokurtic distribution and leverage effect exist in the Nigerian Stock Exchange returns.

Onwukwe, Samson and Lipcsey (2014) studied modeling and forecasting daily returns volatility of Nigerian Banks Stocks and the results revealed the existence of volatility clustering, leptokurtic distribution and leverage effect in the daily returns of Nigerian Banks Stocks.

Aliyu (2009) in his study opined that volatility clustering, leptokurtic distribution and leverage effect exist in the daily returns of Nigerian stocks. 


\section{Methodology}

Returns

Most financial studies involve returns, instead of prices of assets. Campbell, Lo, and Mackindlay (1997) give two main reasons for using returns. First, for average investors, return of an asset is a complete and scale free summary of the investment opportunity. Second, returns series are easier to handle than price series because the former have more attractive statistical properties. The returns can be defined as follows

$$
R_{t}=\log \left(\frac{P_{t}}{P_{t-1}}\right)=\log P_{t}-\log P_{t-1}
$$
time $\mathrm{t}-1$.

where $P_{t}$ is the share price at time t, and $P_{t-1}$ is the share price at

The series $\left\{R_{t}\right\}$ is referred to as the returns series (Karlsson, 2013)

\section{Autoregressive Moving Average (ARMA) Process}

A natural extension of pure autoregressive and pure moving average processes is the mixed autoregressive moving average ( $A R M A)$ processes, which includes the autoregressive and moving average as special cases (Wei, 2006).

A stochastic process $\left\{R_{t}\right\}$ is an $\operatorname{ARMA}(p, q)$ process if $\left\{R_{t}\right\}$ is stationary and if for every $t$,

$$
\varphi(B) R_{t}=\theta(B) a_{t}
$$

$\varphi(B)=1-\varphi_{1} B-\varphi_{2} B^{2}-\cdots-\varphi_{p} B^{p}$ is the autoregressive coefficient polynomial.

$\theta(B)=1-\theta_{1} B-\theta_{2} B^{2}-\cdots-\theta_{q} B^{q}$ is the moving average coefficient polynomial.

\section{ARCH Model}

The first model that provides a systematic framework for modeling volatility is the ARCH model of Engle (1982). Specifically, an ARCH (q) model assumes that,

$$
\begin{aligned}
& R_{t}=\mu_{t}+a_{t}, \quad a_{t}=\sigma_{t} e_{t}, \\
& \sigma_{t}^{2}=\alpha_{0}+\alpha_{1} a_{t-1}^{2}+\cdots+\alpha_{q} a_{t-q}^{2}
\end{aligned}
$$

where $\left[e_{t}\right]$ is a sequence of independent and identically distributed (i.i.d.) random variables with mean, zero, and variance, 1, $\alpha_{0}>0$, and $\alpha_{1}, \ldots, \alpha_{q} \geq 0$. The coefficients $\alpha_{i}$, for $i>0$, must satisfy some regularity conditions to ensure that the unconditional variance of $a_{t}$ is finite. 


\section{Data Analysis And Discussion}

Daily closing share prices of First Bank of Nigeria were obtained from the Nigerian Stock Exchange (NSE) for a period spanning from January 4, 2000 to December 31, 2013. This series consists of 3464 observations.

In the preliminary analyses, we assessed the time series plots of the share price series and the returns series which is the first difference of the log of the share price series.

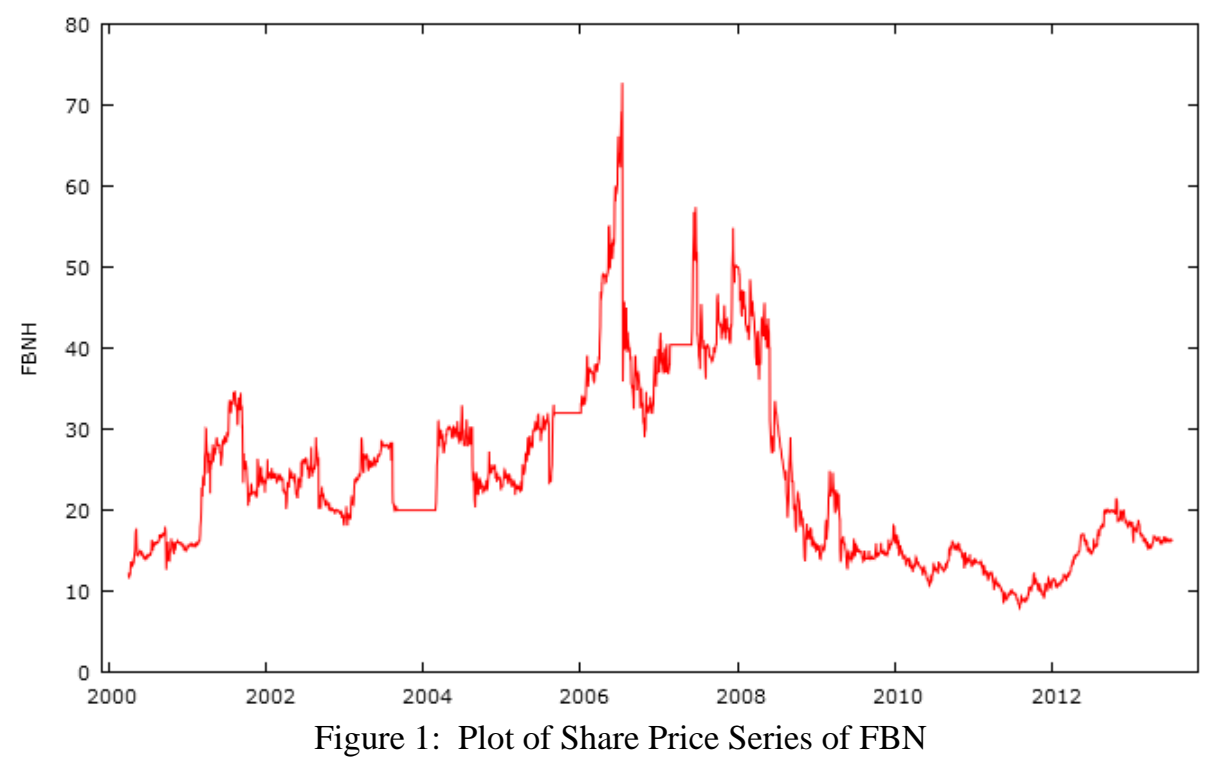

The plot of share price series of FBN (Figure 1) appears to contain a trend component which suggests that the series is non-stationary

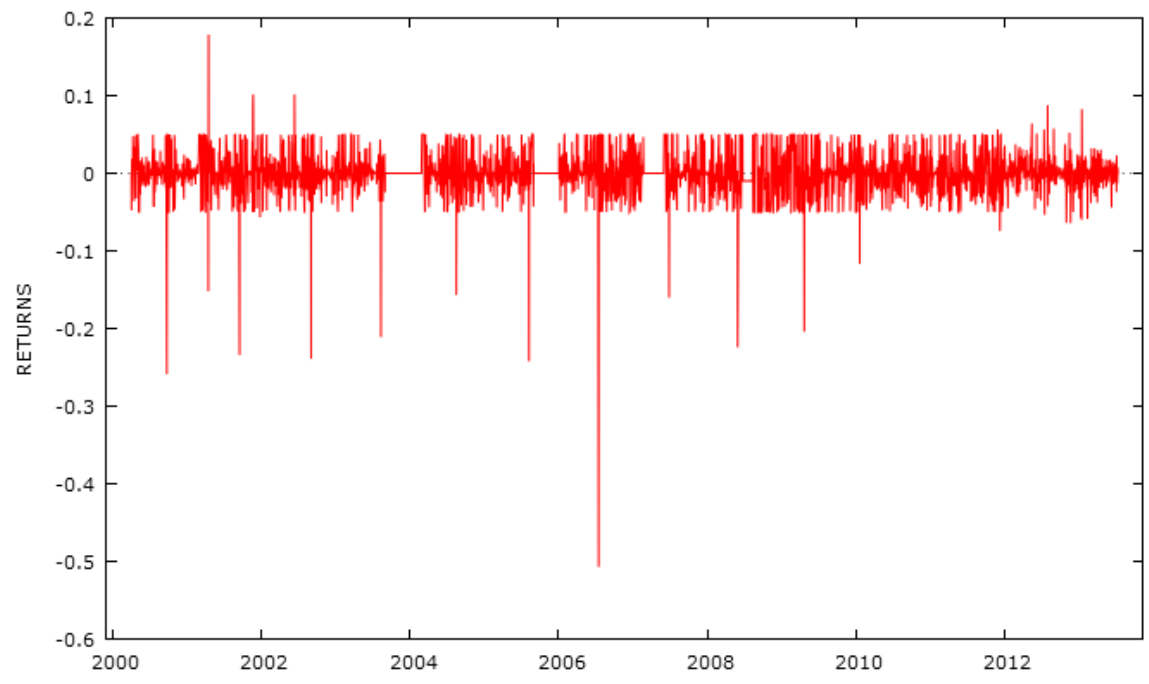

Figure 2: Plot of Returns Series of FBN 
The plot of the returns series (Figure 2) suggests that volatility clustering is quite evident and the series appears to be stationary. We also applied the Augmented Dickey- Fuller (ADF) test to the share price series and the returns series to test for the presence of unit root. The results from (Table 1) show that the test fails to reject the null hypothesis of a unit root for the share price series while the results from (Table 2) show that the test rejects the null hypothesis of a unit root for the returns series. Thus, the results of ADF test show that the share price series is non-stationary while the returns series is stationary.

Table 1: Output of Augmented Dickey Fuller Test for Share Price Series

Null Hypothesis: FBN has a unit root

Exogenous: Constant, Linear Trend

Lag Length: 1 (Automatic - based on SIC, maxlag=60)

\begin{tabular}{cccc}
\hline \hline & t-Statistic & Prob.* \\
\hline \hline Augmented Dickey-Fuller test statistic & -3.102993 & 0.1057 \\
\hline Test critical values: & 1\% level & -3.960691 & \\
& 5\% level & -3.411104 & \\
& 10\% level & -3.127375 & \\
\hline \hline
\end{tabular}

*MacKinnon (1996) one-sided p-values.

Table 2: Output of Augmented Dickey Fuller Test for Return Series

Null Hypothesis: D(FBN) has a unit root

Exogenous: Constant, Linear Trend

Lag Length: 4 (Automatic - based on SIC, maxlag=60)

\begin{tabular}{|c|c|c|c|}
\hline & & t-Statistic & Prob.* \\
\hline \multicolumn{2}{|c|}{ Augmented Dickey-Fuller test statistic } & -29.95644 & 0.0000 \\
\hline \multirow[t]{3}{*}{ Test critical values: } & 1\% level & -3.960694 & \\
\hline & $5 \%$ level & -3.411105 & \\
\hline & $10 \%$ level & -3.127376 & \\
\hline
\end{tabular}

*MacKinnon (1996) one-sided p-values.

\section{Linear Model Identification and Estimation}

The tentative ARMA models for FBN returns series based on the autocorrelations and partial autocorrelations would be $\operatorname{ARMA}(1,1)$, $\operatorname{ARMA}(2,2)$ and ARMA $(3,3)$ with their information criteria shown in Table 3 below: 
Table 3: Information Criteria

\begin{tabular}{|c|c|c|c|}
\hline & ARMA(1,1) & ARMA(2,2) & ARMA(3,3) \\
\hline AIC & -14581.00 & -14609.61 & -14608.10 \\
\hline SIC & -14556.40 & -14572.71 & -14558.90 \\
\hline HQIC & -14572.21 & -14596.44 & -14590.53 \\
\hline
\end{tabular}

$\operatorname{ARMA}(2,2)$ is the model with the smallest information criteria with only the constant term not significant, hence, the selected model for FBN returns series is the $\operatorname{ARMA}(2,2)$ without the constant term shown in equation (4.1)

$$
\begin{array}{crrr}
R_{t}= & 1.0532 R_{t-1}-0.4075 R_{t-2}+0.2668 a_{t-2} & -0.9368 a_{t-1}+ \\
a_{t} & (0.0945) & (0.0954) & (0.1017)
\end{array}
$$

(4.1)

$$
\begin{array}{lllll}
\text { z-ratio: } & (11.1449) & (-4.2697) & (2.6221) & (-9.4420) \\
\text { p-value: } & \left(1 \times 10^{-4}\right) & \left(1 \times 10^{-4}\right) & \left(8.7 \times 10^{-3}\right) & \left(1 \times 10^{-4}\right)
\end{array}
$$

AIC $=-14611.58, \quad$ SIC $=-14580.83, \quad$ HQIC $=-14600.60$ and Qstatistic $=33.8419$ with p-value 0.992 at lag 60 [Excerpts from Table 4].

Table 4: Output of ARMA(2,2) Model without a Constant Term.

Model 7: ARMA, using observations 2-3464 $(\mathrm{T}=3463)$

Dependent variable: ld_FBN

Standard errors based on Hessian

$\begin{array}{llllll} & \text { Coefficient } & \text { Std. Error } & Z & p \text {-value } & \\ \text { phi_1 } & 1.05321 & 0.0945018 & 11.1449 & <0.0001 & * * * \\ \text { phi_2 } & -0.407523 & 0.0954444 & -4.2697 & <0.0001 & * * * \\ \text { theta_1 } & -0.936755 & 0.0992112 & -9.4420 & <0.0001 & * * * \\ \text { theta_2 } & 0.266759 & 0.101735 & 2.6221 & 0.0087 & * * *\end{array}$

$\begin{array}{cccc}\text { Mean dependent var } & 0.000084 & \text { S.D. dependent var } & 0.029658 \\ \text { Mean of innovations } & 0.000090 & \text { S.D. of innovations } & 0.029303 \\ \text { Log-likelihood } & 7310.790 & \text { Akaike criterion } & -14611.58 \\ \text { Schwarz criterion } & -14580.83 & \text { Hannan-Quinn } & -14600.60\end{array}$

\section{Identification of ARCH Effect}

For ease in notation, let $a_{t}=R_{t}-\mu_{t}$ be the residuals of the mean equation. The squares of series, $a_{t}^{2}$ is then used to check for conditional heteroscedasticity, which is also known as the ARCH effects. If at least one lag term in the squares of residual series is found to be statistically significant, this confirms the presence of ARCH effects (Khan and Azim, 2013). To perform the test, the usual Ljung-box statistic, Q(m), is applied to the $\left\{a_{t}^{2}\right\}$ series (Mcleod and $\mathrm{Li}, 1983$ ). The null hypothesis is that, the first $\mathrm{m}$ lags of ACF of the $a_{t}^{2}$ series are zero. This implies that ARCH effects do not exist in $a_{t}^{2}$. The null hypothesis is rejected at 5\% significance levels if the 
probability value corresponding to the Q-statistic is less than the level of significance.

Another approach for testing the ARCH effects is to apply the Lagrange Multiplier (LM) test of ARCH(q) against the hypothesis of no ARCH effects to $\left\{a_{t}^{2}\right\}$ series. The LM test is carried out by computing, $\chi^{2}=$ $\mathrm{T} R^{2}$ in the regression of $a_{t}^{2}$ on a constant and q lagged values. $\mathrm{T}$ is the sample size and $R^{2}$ is the coefficient of determination. Under the null hypothesis of no ARCH effects, the statistic has a Chi-square distribution with q degrees of freedom. If the LM test statistic is larger than the critical value, then, there is evidence of the presence of ARCH effects (Greene, 2002).

After taking the residual series of the estimated $\operatorname{ARMA}(2,2)$ model, which was selected on the basis of the significance of all its parameters, we check if there exists any ARCH effect or not in the residuals.

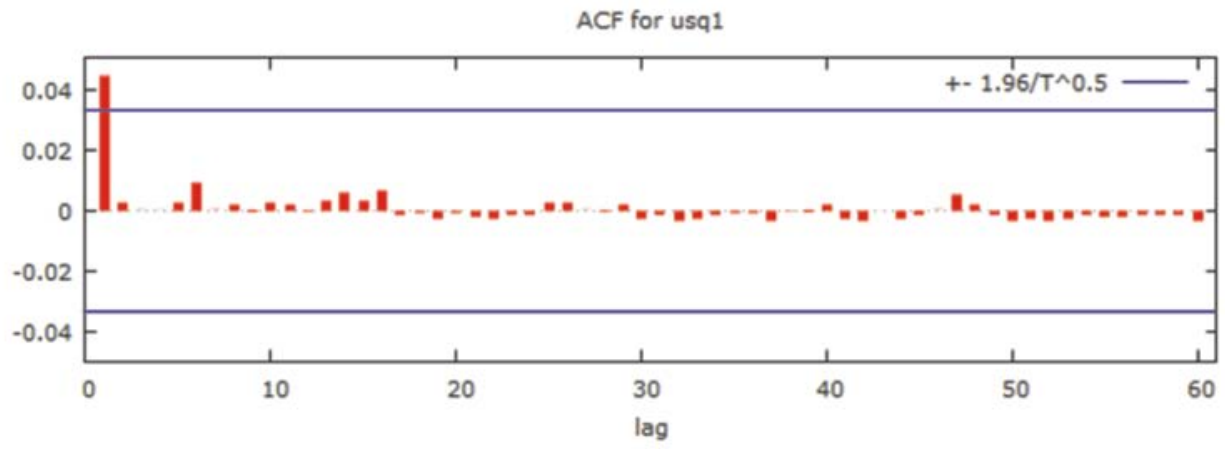

Figure 3: ACF of Squares of Residuals of $\operatorname{ARMA}(2,2)$

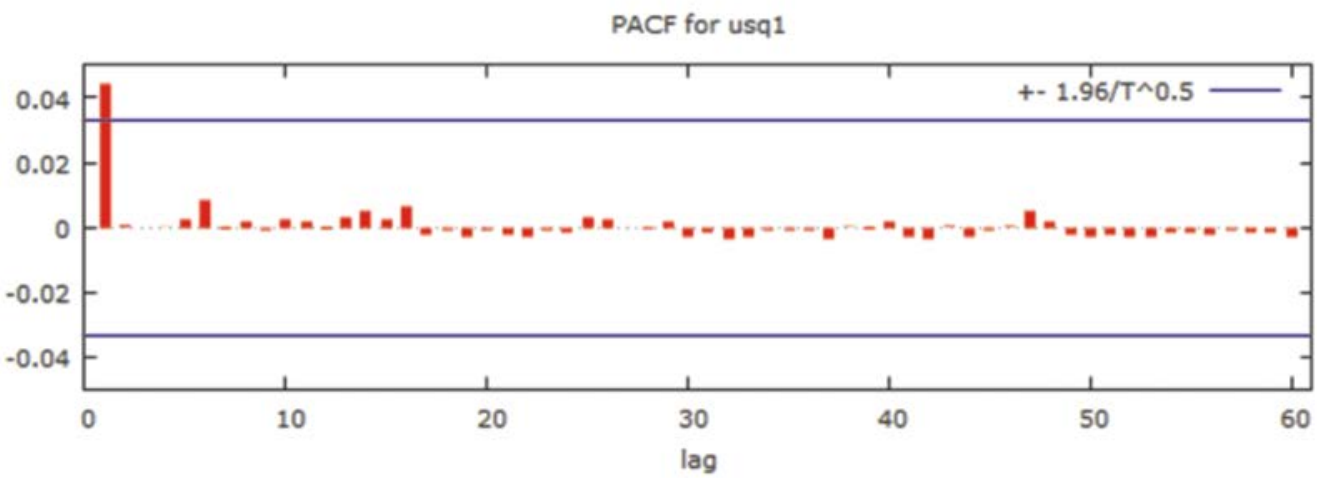

Figure 4: PACF for Squares of Residuals of ARMA(2,2) Model

From (Figures 3 and 4) respectively, the ACF and the PACF of the squares of residuals exhibit significant spike at lag 1 while dying down to zero fast, indicating the presence of ARCH effect. In order to test statistically 
for the presence of ARCH effect, the Lagrange Multiplier (LM) test is applied to the squares of the residuals. According to Table 5,

Table 5: Lagrange Multiplier Test for ARCH effects Heteroscedasticity Test: ARCH

\begin{tabular}{cccc}
\hline \hline F-statistic & 6.740571 & Prob. F(1,3458) & 0.0095 \\
Obs*R-squared & 6.731348 \\
\hline \hline
\end{tabular}

the hypothesis of no ARCH effects is rejected at 5\% level of significance since the LM test statistic $=6.7313$ at lag $1>\chi_{0.05,1}^{2}=3.841$ with corresponding p-value 0.0095 .

Also, evidence from Ljung and Box Q-Statistic confirms that ARCH effects exist in the squares of the residuals at lag 1 since 0.009 .

Q-statistic $=6.7592>\chi_{0.05,1}^{2}=3.841$ with corresponding p-value

Therefore, it is concluded that ARCH effects exist in the returns series and can be modeled using ARCH(1) model as shown in equation (4.2) below

$$
\begin{aligned}
& R_{t}=-1.9894 e^{-3}+a_{t} \text {, } \\
& \text { s.e: } \quad\left(3.612 \times 10^{-4}\right) \\
& \text { z-ratio: } \quad(-5.5077) \\
& \text { p-value: } \quad(0.0001) \\
& \sigma_{t}^{2}= \\
& 4.0155 e^{-4}+ \\
& 0.850956 a_{t-1}^{2} \\
& \text { s.e: } \quad\left(1.5134 \times 10^{-5}\right) \\
& \text { z-ratio: (26.5323) } \\
& \text { p-value: } \quad\left(1 \times 10^{-4}\right) \\
& \left(1 \times 10^{-4}\right)
\end{aligned}
$$

[Excerpts from Table 6].

Table 6: Output of ARCH (1) Model

Model 6: GARCH, using observations 2-3464 ( $\mathrm{T}=3463)$

Dependent variable: uhat1

Standard errors based on Hessian

$\begin{array}{cccccc} & \text { Coefficient } & \text { Std. Error } & \mathrm{z} & \mathrm{p} \text {-value } & \\ \text { Const } & -0.0019894 & 0.000361202 & -5.5077 & <0.0001 & * * * \\ & & & & & \\ \text { alpha(0) } & 0.00040155 & 1.51344 \mathrm{e}-05 & 26.5323 & <0.0001 & * * * \\ \text { alpha(1) } & 0.850956 & 0.0586056 & 14.5201 & <0.0001 & * * *\end{array}$

$\begin{array}{cccr}\text { Mean dependent var } & 0.000090 & \text { S.D. dependent var } & 0.029308 \\ \text { Log-likelihood } & 7699.888 & \text { Akaike criterion } & -15391.78 \\ \text { Schwarz criterion } & -15367.18 & \text { Hannan-Quinn } & -15382.99\end{array}$


Under the diagnostic checking of the ARCH(1) model, the parameter of ARCH (1) model is statistically significant. The LM test indicates that there is no ARCH effect in the residuals (Table 7),

Table 7: Lagrange Multiplier Test for ARCH(1) Model

Heteroscedasticity Test: ARCH

\begin{tabular}{cccc}
\hline \hline F-statistic & 0.214213 & Prob. F(1,3458) & 0.6435 \\
Obs*R-squared & 0.214324 & Prob. Chi-Square(1) & 0.6434 \\
\hline \hline
\end{tabular}

since $\mathrm{LM}=0.2143$ at lag $1<\chi_{0.05,1}^{2}=3.841$ with corresponding probability value of 0.6434 . Also, evidence from Q-statistic confirms that the model is adequate since Q-statistic $=5.8756$ at lag $60<\chi_{0.05,59}^{2}=77.931$ with corresponding probability value of 1.000 .

\section{Conclusion}

This study provides evidence to show that $\operatorname{ARMA}(2,2)$ model is found to be adequate in the modeling the linear dependence in the returns of First Bank of Nigeria while the ARCH(1) model is adequate in modeling the changing conditional variance in the returns of First Bank of Nigeria. Therefore, combining the two models results in a simple ARMA(2,2)ARCH(1) model that completely models the returns series of First Bank of Nigeria.

\section{References:}

Aliyu, S. U. R. (2009). "Does Inflation have an Impact on Stock Returns and Volatility?" Evidence from Nigeria and Ghana. Available at www.csae.ox.ac.uk/conferences/2011-edia/papers/054-aliyu.pdf. Extracted 5 August, 2014.

Asteriou, D. and Hall, S. G. (2007). Applied Econometrics. A Modern Approach. New York, Palgrave Macmillan.

Atoi, N. V. (2014). Testing Volatility in Nigerian Stock Market Using GARCH Models. Central Bank of Nigeria Journal of Applied Statistics, 5(2). Brunhart. A. (2011). Evaluating the Effect of "Zumwinkel-Affair" and Financial Crisis on Stock Prices in Liechtenstein: An "Unconventional" Augmented GARCH-Approach. Available at https://mpra.ub.unimuenchen.de/42047/1/MPRA_paper_42047.pdf.

Extracted 16 September, 2014.

Campbell, J. Y, Lo, A. W. and Mackinlay, A. C. (1997). The Econometrics of Financial Markets. New Jersey, Princeton, pp. 27-88.

Engle, R. F. (1982). Autoregressive Conditional Heteroscedasticity with Estimates of the Variance of United Kingdom Inflations. Econometrica, 50:987-1007. 
Fan, J. and Yao, Q. (2003). Nonlinear time series: Nonparametric and Parametric methods,

New York, Springer.

Greene, W. H. (2002). Econometric Analysis. $5^{\text {th }}$ ed., New York, Prentice Hall, p. 269.

Karlsson L. (2013). Theoretical Survey, Model Implementation and Robustness Analysis. Unpublished Masters Dissertation. Available at www.math.kth.se/matstat/02061b.htm. Extracted 1 August, 2014.

Khan, A. J. and Azim, P. (2013). One-Step Ahead Forecastability of GARCH(1,1): A Comparative Analysis of USD and PKR Based Exchange Rate Volatility. The Labour Journal of Economics, 18(1):1-38.

Mcleod, A. I. and Li, W. K. (1983). Diagnostic Checking ARMA Time Series Models using Squared Residuals Autocorrelations. Journal of Time Series Analysis, 4:269-273.

Mgbame, C. O. and Ikhatua, O. J. (2014). Accounting Information and Stock Volatility in the Nigerian Capital Market: A GARCH Analysis Approach. International Review of Management and Business Research, 2 (1).

Onwukwe, C. E., Samson, T. K and Lipcsey Z. (2014). Modeling and Forecasting daily returns volatility of Nigerian Banks Stocks. Available at eujournal.org/index.php/esj/article/347. Extracted 9 February, 2014.

Wei, W. W. S. (2006). Time Series Analysis Univariate and Multivariate Methods, $2^{\text {nd }}$ ed., Adison Westley. 